\title{
Introduction of Pack Test for Participative Environmental Monitoring and Environmental Education for Sustainability in Malaysia
}

\author{
Muhammad Faiz* \\ Faculty of Civil Engineering, Universiti Teknologi Malaysia \\ Skudai, Johor, 81310 Malaysia
}

\begin{abstract}
Pack Test which provided by Kyoritsu Chemical-Check Lab. Corporation has been assumed as a professional easy-to-use onsite water quality checker. The aim of this study is to examine the possibility of application of Pack Test in Malaysia, and to assess the required matters during introduction processes. Two workshops were sampled to prove the potential function of Pack Test in environmental education and participative environmental monitoring. Two hours lecture of Universiti Teknologi Malaysia (UTM) was facilitated as a workshop by author on September 23, 2010, and then the author has assisted a workshop in Putrajaya on October 9, 2010. Questionnaire forms were applied to test as if people's feeling are positive or not towards Pack Test as preliminary research. Water quality parameters were simultaneously measured by Pack Test, such as, COD, $\mathrm{NO}^{3-}$, $\mathrm{CI}^{-}$, and $\mathrm{NH}_{4}{ }^{+}$in UTM, pH and $\mathrm{NO}^{3-}$ were measured in Putrajaya workshop, respectively. Participants' feeling in the both workshops showed strong positive potential for Pack Test. The results of water qualities from UTM workshop had big variation in COD and $\mathrm{NO}_{3}$. Considering the reason, the UTM workshop was conducted without proper support for both facilitators and participants. Participants were able to classify the water quality level in a short time. As for the Putrajaya workshop, with deep support and well skilled instruction by facilitator team, the data showed small variation i.e. good and consistent water quality result. It is obvious that Pack Test is always applicable to assess water environment and it is well functioned as user friendly easy-to-use water quality checker. Thereby the role of Pack Test is segregated from conventional standard methods. The participants' feeling to Pack Test was highly positive for implementation in order to improve public environmental awareness. Simultaneously, they were feeling that people can participate more effectively in water environment issues by Pack Test. It was clear that Pack Test was notable in-situ water quality checker, which has advantages over its particular methods that never rely on transport of samples to a distant laboratory for chemical analysis. Above all, it could be a breakthrough point to empower public participation, and environmental education for water sustainability. In addition, it can be pointed out that if there are chance to get skilled of the usage of Pack Test, which will be important for teachers, engineers, and other potential facilitators to ensure the effective usage of Pack Test towards.
\end{abstract}

Keywords: Environmental awareness, Public participation, Simplify environmental monitoring tool, Strategic environmental assessment, Water quality.

\section{Introduction}

Many of the social and environmental problems faced by industrial societies will not be solved without a fundamental re-think of how citizens and organizations interact with the environment [1]. Environmental issues are best handled with the participation of all concerned citizens where each individual should have appropriate access to information concerning the environment that is held by public authorities and the opportunity to participate in

\footnotetext{
*Corresponding address:

Muhammad Faiz

Faculty of Civil Engineering,

Universiti Teknologi Malaysia,

Skudai, Johor, 81310 Malaysia

Email :mr_faiz@yahoo.com.my
}

decision-making processes [2]. It is inevitable trend that the public participation must be integrated in environmental matters, because it allows information relevant with democratic decision-making process to be included and it increases the integrity of the selected programs, plans, and policies [3]. Our ecosystem is moving into a new situation where environmental information is tightly related to public participation in decision-making and awareness of environmental matters [2,3,4,5].

Environmental impact assessment (EIA) is a practice that develops in an evolutional world [6]. According to several authors, environmental assessment is entering a postclassical rational planning phase $[7,8]$, i.e. it is time to link technical approaches to socio-political debates, increasingly prominent via multiple negotiations 
that are at the core of decision-making process [3]. Because, it is critical that science on its own, without a process of consideration and argument amongst a wide range of stakeholders cannot provide guidance on the 'best' options for a future action [1]. Strategic environmental assessment (SEA) is a challenge to overcome this matter [3]. For instance, public participation in SEA is in a process of implementation and has ability to influence public environmental awareness level [3]. Public participation (PP) is a process where individuals, groups and organizations decide to take an active role in making decisions that affected them and allowing people to influence the outcome of plans and working processes [4]. Mouratiadou \& Moran [9], have stated that if stakeholders are not involved in the evaluation of water management policy measures, the decisions taken can be controversial and generate public opposition, thus making those decisions unfeasible. Such implementation gap is expected to be cleared to know the importance of PP nowadays [9].

On the other hand, environmental education for sustainability (EES) focuses on developing a well-informed, responsible public who "has the potential as an exemplary vehicle for what many believe all of education should consider its primary function: furthering the development of higher-order skills - critical thinking, creative thinking, integrative problem-solving thinking" [10]. Kikuchi et al. [4] has stated that leanercentred practices or experimental base education in environmental context has potential to enhance public knowledge about environment, and indirectly awaken the public's self motivation to be information creators with critics. Schleicher [11] also supported that experience-based environmental education is necessary. The study conducted by Schleicher [11] supported the importance formative experience from once youth that attitudes towards nature are established in childhood, that environmental behaviour is more determined by personal experiences than by knowledge, and that school teaching has only limited influence.

Huang \& Xia [12] stated that the existence of differently explained water quality information from same data is needed for different management levels, such as data for publics, authorities, specialist, and etc. Thompson [13] also stated that a lot of water quality data have been produced, but there is very little information useful to the public. The factor to continuing improvements in environmental quality is the availability of precise information that is representative of the quality of water bodies [14]. Water quality monitoring and data collection should be driven first and foremost by the domestic and international needs of the public in right way. In line with regarding, the available character for participatory assessment and environmental education is low cost for getting numerous data, time saving for rapid results purpose, and practical, and it can operate even in situations of significant data gaps $[4,15]$. According to Graveline et al. [15], the European Union (EU) Water Framework Directive (WFD) implemented in 2000 requires EU Member States to adapt and to strengthen their monitoring of aquatic ecosystems. Thus, they designed new monitoring strategies and practices that require tool and method that can include rapid delivery of results on-site, low-cost, and capacity to acquire large number of observations within a short time frame.

Thus, we take notice on significant potential of Pack Test (Kyoritsu Chemical-Check Lab. Corporation, Japan; e.g. Kikuchi et al. 2010), which explained in methodology in this paper. According to Kyoritsu Chemical-Check Cooperation, this tool is one of the most simplified water quality checker for professional use. Pack Test is originally has been developed as professional self-management tool for process management engineers of factory effluent and environmental monitoring. Then the usages were extended for environmental education and others. This tool is now expected to be introduced in Malaysia, Indonesia and other South-eastern Asian countries [4]. Hereby, Pack Test is already used by Japanese companies and others in Singapore as environmentally selfmanagement tool. Of course, it is required to examine their credibility, reproducibility and sensitivity for environmental samples by user or suitable party in tropical area. On top with regarding these, it was assumed this matter as future work. Then in this study, it was brought out the aim of this study as to examine the possibility of application of Pack Test on SEA and EES in Malaysia, and to assess the required matters during introduction processes.

\section{Materials and Methods Pack Test}

Pack Test (Figure 1) had originally invented by Kyoritsu Chemical-Check Lab. Corporation, in order to monitor factory effluent and environment matter, after the water pollution presentation act was implemented in Japan in 
1971. The property of Pack Test through its characters such as easy-to-use, small, rapid to know result, low cost, and onsite, has been helping the engineers for water quality monitoring. It is a professional-use tool, which can be used at anywhere without any laboratory facilities. On the other hand, because of the particular charicter, this tool can be used from elementary school students, so that, wide application were already implemented in Japanese environmental education by this water quality test kit. There are more than 60 parameters in total, such as, phospate, $\mathrm{pH}$, heavy metals, and etc (Kyoritsu Chemical-Check Lab. Corporation; Kikuchi et al. 2010). Principle of Pack Test, and a lot of parameter of Pack Tests are based on Japanese Industrial Standard, and have firm footing on chemical discipline. It already has been applied for a lot of scientific researches, as well as experiment in governmental institute, factory, and environmental educations. The main applications fields are simple water check for factory effluent, simple check for drinking water, and application for environmental researches and educations. Pack Test is a tool that brings batch methods of chemical experiment on site by one of the simplest way, which eliminates several experimental processes, such as sample transported to a distant laboratory, storage, and lab-technical experimental procedures. Then, its own unique function is produced.

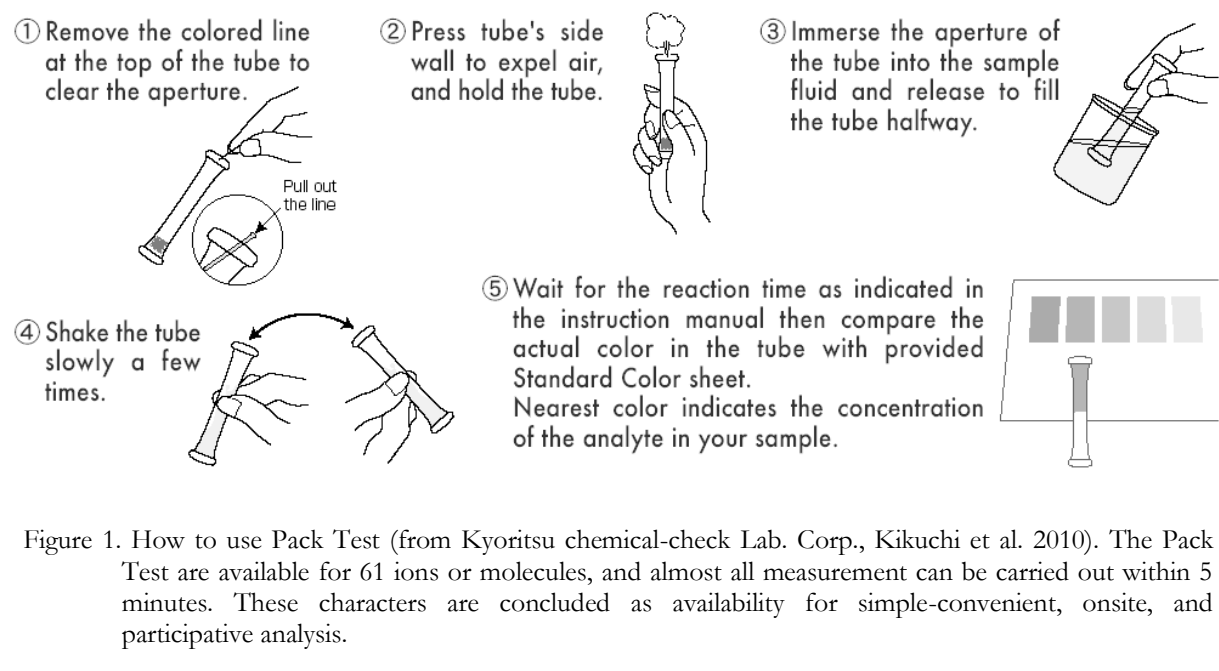

\section{Comparison of two workshops}

Pack Test is a newly being introduced tool in Malaysia, so that model experiments for introduction are appropriate to determine considerable points to be cared. Accordingly, two workshops were sampled to compare the potential function of Pack Test in environmental education and participative environmental monitoring by two types of student group. It was inspected the applicability of Pack Test which enables participants easily gain knowledge about water quality. The target groups were university students who enrolled in a water environmental course and high school students. Two hours lecture of Universiti Teknologi Malaysia (UTM) by Dr. Kikuchi in faculty of civil engineering was applied to a water environmental workshop on September 23, 2010. The workshop was facilitated by author completely, and then the author has assisted on another workshop in Putrajaya on October 9,
2010, where is the centre of Malaysian government. Recruiting participants for the workshops did not be aimed at a representative sample of the regional population. Instead, an idea was addressed to involve people who are committed to the local society and future environmental issues.

UTM workshop has been held along UTM's river. 15 participants were joined to UTM workshop. They were fourth grade of undergraduate students of UTM. Three conditions of water sources were considered which were tap water, river water, and wastewater from restaurants. In the workshop, four water quality parameters were simultaneously measured by Pack Test, such as, $\mathrm{COD}, \mathrm{NO}_{3}, \mathrm{Cl}^{-}$, and $\mathrm{NH}_{4}{ }^{+}$. The reason $\mathrm{COD}$ and three types of nitrogen had chosen were because, they act as common nutrient and pollute agents in river environment. Discussions about actual water quality level were not aimed in this study, but anyhow it was compared with 
Malaysian water quality standards, such as Malaysian drinking water quality standard, environment quality for industry effluent. Besides that, it was assumed that all results from field survey should be same with each group, and it also was assumed that experimental error of field data also has important information. Short description about PackTest were provided after the workshop, and then simple questionnaire forms were distributed for participants. Based on experience and knowledge that 15 respondents had gained through workshop, they were asked about their perception towards the positive potential of Pack Test by questionnaire.

The Putrajaya workshop has been held at a lakeside in Putrajaya area by 57 high school students and 5 staffs. The water quality of $\mathrm{pH}$ and $\mathrm{NO}_{3}$ - were simultaneously analysed, with other physical and biological parameters. In addition, the facilitator in this workshop had prepared tentative indicator for $\mathrm{pH}$ and $\mathrm{NO}_{3}$ - to ensure school students be able to intrepret water quality results. The results were compared to the Malaysian water quality standard explained above. After the workshop, short description about PackTest was provided, then simple questionnaire forms have been distributed among participants, as well as the UTM workshop.

\section{Questionnaire}

Questionnaire forms were applied to test if people's feeling were positive or not towards Pack Test as preliminary research. Five questions have been asked. The questionnaires were closed-ended questions type and used the simplest form of closed-ended questions which is Yes/No question. The first question was asked about whether the participants have ever used any simplified water quality monitoring tool (Q1). Secondly, participants were asked whether they agree or not that Pack Test can increase environmental awareness among publics (Q2). Third question was about their knowledge in using Pack Test (Q3). Then, participants were asked whether they have picture about Malaysian water quality standard or not (Q4). The last question was about whether participants agree or not that Pack Test can help people to know waters environmental quality level (Q5).

\section{Result UTM Workshop}

The water quality of $\mathrm{COD}, \mathrm{NO}_{3}, \mathrm{Cl}$, and $\mathrm{NH}_{4}{ }^{+}$ were shown in Table 1. The results for $\mathrm{NH}_{4}{ }^{+}$ performed with smaller variation, i.e. the concentration were within the same order. COD also performed better results except group 4, as Group 4 accidentally used high range COD Pack Test to measure water quality for river water. Group 3 was not able to complete their monitoring activity as for tap water COD cheking. Moreover, it was against the assumption, there were bigger variation for $\mathrm{NO}_{3}{ }^{-}$data with each group results. It was because group 2 and group 3 accidentaly had used high range $\mathrm{NO}_{3}-$ Pack Test. As for $\mathrm{Cl}$, it showed only small variation of data. Fig. 2 shows overall questionnaire results in UTM workshop. For the first question, 10 of 15 respondents were never ever had used simplified water quality monitoring tool. Hereby, 5 respondents had answered based on their experience gained in the workshop. Second question shows that all the respondents agreed that simplified water quality checker is useful to increase people's environmental awareness. While third question showed that 14 of 15 respondents knew how to use Pack Test after joined the workshop. Next, questionnaire results showed that 10 of 15 respondents did not have clear image about Malaysia water quality standard. As for questionnaire resulted by the Putrajaya workshop was compared with tentative indicators which prepared by organizer. The last question result indicated that all respondents agreed that PackTest can enable anybody capable to know water quality condition easily and will help public to know water environment by Pack Test.

Table 1. Results of water quality analysis by the workshop in UTM.

\begin{tabular}{|c|c|c|c|c|c|}
\hline & & Group & Tap water & River water & Wastewate \\
\hline COD & {$[\mathrm{mg} / \mathrm{L}]$} & $\begin{array}{l}1 \\
2 \\
3 \\
4\end{array}$ & $\begin{array}{c}5.0 \\
5.0 \\
* \\
5.0\end{array}$ & $\begin{array}{r}15 \\
13 \\
10 \\
100\end{array}$ & $\begin{array}{r}70 \\
80 \\
100 \\
75\end{array}$ \\
\hline $\mathrm{NH}_{4}{ }^{+}-\mathrm{N}$ & {$[\mathrm{mg} / \mathrm{L}]$} & $\begin{array}{l}1 \\
2 \\
3 \\
4\end{array}$ & $\begin{array}{l}\text { ND } \\
0.1 \\
\text { ND } \\
0.2\end{array}$ & $\begin{array}{l}0.5 \\
0.2 \\
0.2 \\
1.5\end{array}$ & $\begin{array}{l}3.5 \\
1.5 \\
3.5 \\
3.5\end{array}$ \\
\hline $\mathrm{Cl}^{-}$ & {$[\mathrm{mg} / \mathrm{L}]$} & $\begin{array}{l}1 \\
2 \\
3 \\
4\end{array}$ & $\begin{array}{l}0.15 \\
\text { ND } \\
0.1 \\
0.15\end{array}$ & $\begin{array}{l}\mathrm{ND} \\
0.1 \\
0.1 \\
0.7\end{array}$ & $\begin{array}{l}\text { ND } \\
\text { ND } \\
\text { ND } \\
0.1\end{array}$ \\
\hline $\mathrm{NO}_{3}^{-}$ & {$[\mathrm{mg} / \mathrm{L}]$} & $\begin{array}{l}1 \\
2 \\
3 \\
4\end{array}$ & $\begin{array}{r}1.0 \\
90 \\
20 \\
2.0\end{array}$ & $\begin{array}{l}\mathrm{ND} \\
157.5 \\
20 \\
1.0\end{array}$ & $\begin{array}{r}\mathrm{ND} \\
90 \\
\mathrm{ND} \\
1.5\end{array}$ \\
\hline
\end{tabular}




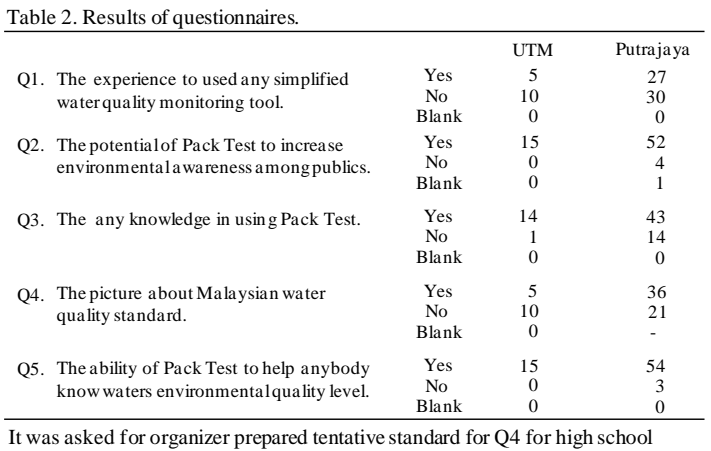
students in Putrajaya workshop.

\section{Putrajaya Workshop}

The water quality data of $\mathrm{pH}$ and $\mathrm{NO}_{3}$ measured by Pack Test were shown in Table 3 . Water quality were measured by repetition of each group. The results for $\mathrm{pH}$ and $\mathrm{NO}_{3}$ performed with smaller variation, i.e. the values showed same order. Figure 2 shows overall questionnaire resulted from Putrajaya workshops. For the first question, 30 of 57 respondents were never ever had used any simplified water quality monitoring tool. Second question showed that 52 of 56 respondents agreed that simplify water quality checker is useful to increase people's environmental awareness. While third question resulted that 43 of 57 respondents knew how to use PackTest after joined the workshop. Next, it showed that 36 of 57 understood the organizer standard after the workshop. Last question result indicated that 54 of 57 participants agreed that Pack Test can enable anybody to know water quality condition easily and helping for public to know water environment.

Table 3. Results of water quality analysis by the workshop in Putrajaya.

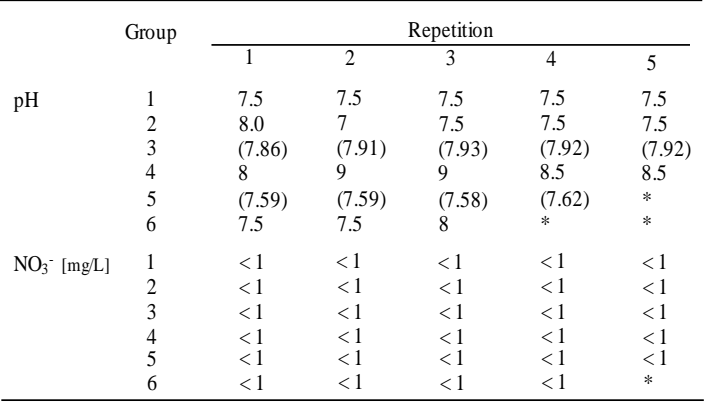

The data are just as reported by experimenters. *: no time to check water qua lity. The data in parentheses are measured by erector $\mathrm{pH}$ probe.

\section{Discussion}

In this study, the participants were able to classify the water quality level in a short time by using Pack Test. According to author's observation, during the two workshops, it was clear that Pack Test is notable in-situ water quality checker, which has advantages over its particular methods that never rely on transport of samples to a distant laboratory for chemical analysis. Thus, the participants easily could get water quality result using Pack Test. The product design, which eliminates some steps, such as preservation, transport and storage, allows the simplification of the analytical procedure, accordingly it enabled the experimenter access to appropriate water environmental information. Based on this character, it is considered that everybody who interested in water quality could tightly be related with water quality data by their own experience. This can be breakthrough point for public participation, and environmental education for water sustainability.

In order to consider the applicability of this tool, the detection range of Pack Test has shown by standard colour chart, and it was compared to four considerable environmental standards (Fig. 2), following these, National Water Quality Standard (WQS): environmental quality report (2006), department of environment, ministry of natural resources and environment. Environmental quality (EQ) for industry effluent; A applies to areas upstream of the water intakes: environmental quality (Sewerage and Industrial Effluents) regulations (1974), department of environment, ministry of natural resources and environment, Malaysia. Drinking water quality standard (DWS): RW (raw water); EF (effluent), engineering services division, ministry of health Malaysia (2009).

It is obvious that Pack Test such as for $\mathrm{pH}$ and COD completely applicable to check water quality standard. As for $\mathrm{NH}_{4}{ }^{+}$, it is applicable to assess water environment level of class II to $\mathrm{V}$ in Malaysia (Fig. 2). Moreover it is possible for Pack Test to assess environment quality standard A or standard B for all these selected parameters. Simultaneously, it also capable of assessing Malaysia's drinking water quality standard. 

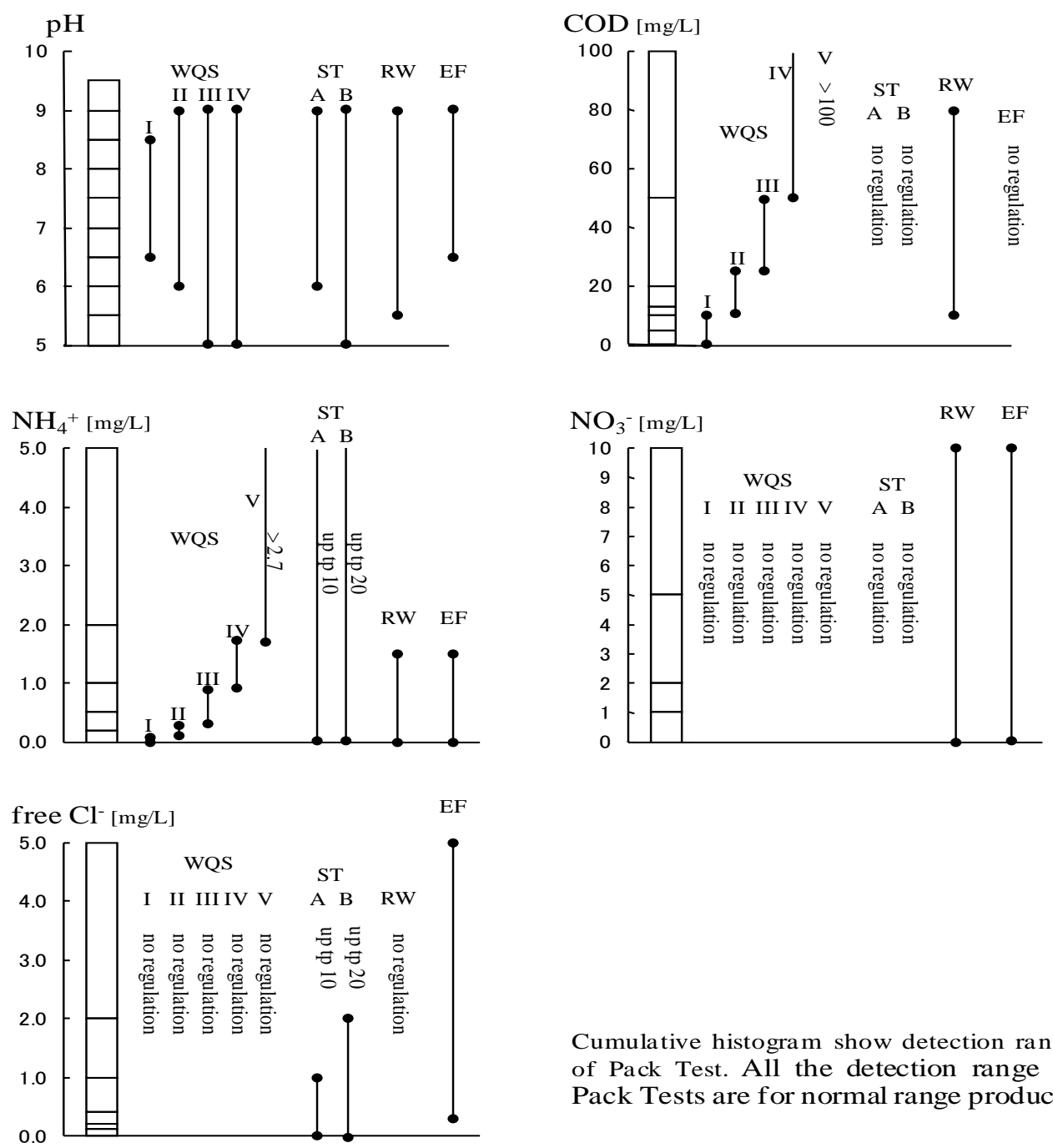

Cumulative histogram show detection range of Pack Test. All the detection range of Pack Tests are for normal range products.

Figure 2. Comparison between detection range of Pack Test and environmental water quality standards in Malaysia. WQS: National Water Quality Standard, Environmental quality report (2006), department of environment, ministry of natural resource and environment (DOE). ST: Environmental quality (industry effluent) . A applies to areas upstream of the water intakes). Environmental Quality (Sewerage and Industrial Effluents) Regulations (1974), DOE, Malaysia. RW (raw water), EF(effluent): Drinking water quality standard. Engineering services division, ministry of health Malaysia (2009).

According to WQS, the $\mathrm{NH}_{4}{ }^{+}$concentration for wastewater effluent that discharged into UTM's river was within class IV to $\mathrm{V}$, and that of UTM's river water quality was within class II to III. As for COD, the concentration for wastewater effluent that discharged into the river was within class IV, and that of UTM's river water quality was within class II. $\mathrm{NO}_{3}^{-}$can be compared to Malaysia drinking water quality standard where it comply with the standard. As for $\mathrm{Cl}^{-}$, it can be compared to WQS where the UTM's river meet standard A and it complies with Malaysia drinking water quality standard. As for $\mathrm{pH}$ condition in Putrajaya lake, it meets standard I when compared to WQS. In addition, $\mathrm{pH}$ meet standard A and complies with Malaysia drinking water quality standard.
In addition, we also can see from fig. 2, the detection limit of Pack Test is not suitable to assess $\mathrm{NH}_{4}{ }^{+}$for low concentration water like tap water, i. e. for class I of Malaysia water quality standard. Kikuchi et al., (2010) also stated that it may be difficult to argue the significance of the water quality differences as for low concentration in his research at Ciliwung River, Indonesia. If so, it is able to define Pack Test of $\mathrm{NH}_{4}{ }^{+}$as a tool to assess the degradation of water body, rather not to investigate about detail phenomenon in a clean water body. However, it does not mean the low reliability of this tool. It rather makes clear the importance role of the Pack Test as it segregated from conventional standard methods, and it well functions as user friendly easy-to-use water quality checker. For 
example, during the UTM workshop, they discussed with each other about water quality level using Malaysia water quality standard in the field. Then, indirectly it was expected that they could improve their knowledge about water quality standard in Malaysia and the actual water environment at each of the site. The conventional standard method for water quality analysis does not have such a function. Only easy-to-use water quality checkers can perform the function.

As for the water quality data, even it was assumed that each group should get similar result of water quality, the result of water quality from UTM workshop had big valuation in COD and $\mathrm{NO}_{3}$. Considering the reason, the UTM workshop was conducted without proper support for both facilitators and participants, and initial demonstration for Pack Test to participants also never done. It has lead because of lack of preparation. For example, it was because, due to various type of Pack Test were provided at a time, i.e. $\mathrm{NO}_{3}$ for high range in order to check waste effluent, and low range $\mathrm{NO}_{3}$ - for Pack Test for tap and river water are mixed. Then, participants applied insufficient tool for water quality checking. Such a mistake can be very easily happened. It indicates small matters are the very important points that should be considered, when Pack Test will newly be introduced in Malaysia. Of course, these types of problem are possible to be improved, as if a facilitator is enough skilled and subsidiary materials are separately provided. In fact, these issues are able to be taken into account easily.

Of course the maker of Pack Test has attached enough easy-to-understand manual for all of their products. Accordingly, even there is no support, every user can still apply Pack Test to check water quality easily by themselves. However, from the experience, it can be said that initial supports to use Pack Test was required in UTM workshop. As for the Putrajaya workshop, with deep support and well skilled instruction by facilitator team, it became for small valuation i.e. good and consistent water quality results. Here, we could see the differences between two workshops, where UTM workshop was less good than Putrajaya workshop. Then, it can be point out that there are needs of training in order to get skilled the usage of Pack Test. The training chance for Pack Test will be important for teachers, engineers, and other potential facilitators to ensure the effective usage of Pack Test towards the self management of environment, and environmental education for sustainability. Then, the users, such as, public can focus more on water quality data, and its interpretation.

To apply this kind of simplified tool for participative environmental monitoring as a new wave to involve public in water environmental issues. This concept must contribute to sustainable development especially in water environment aspect via SEA [3] and EES [10], especially experience based environmental education [4], as peoples can easily get reliable their own water quality data access. Referring to the table 2, the both workshops showed strong positive potential for implementation of Pack Test to improve public environmental awareness. The results told that participants had significant positive feeling towards Pack Test and had thought that application of Pack Test enhanced their water environment management knowledge. Simultaneously, they were feeling that people can participate more effectively in water environment issues by using this tool. Considering such results, it is considered that stakeholders also able to have got informed by their activity and possible to discover new skills to maximise the social benefits with other public participants. This must be the critical point that public get participated and be familiar with the social decision-making processes. It is the process of participation and multiple, which itself provide opportunities for learning and changing in personal and social level, respectively [1].

In this paper, author agrees the concept of Kyoritsu Chemical-Check Lab. Corporation, that their Pack Test is professional environmental monitoring tool with various possible applications, such as for, inspection of drinking water, waste water process management, environmental water monitoring, educational purpose, and environmental research. From the observation during the two workshops, it was cleared that participants do not have clear understanding about the Malaysia water quality standard. Pack Test was a new simplified water quality checker and their response towards Pack Test were significantly positive. Accordingly, we can conclude that, water authority has been traditionally only relied on technical experts to overcome environmental problems, but it is required to be changed by increase of environmental awareness that simultaneously take public participation in whole management process [16,17]. Thus, as a new suggestion in Malaysia, it can be said Pack Test have an ability 
to fulfil the gap because of the ease of userfriendly data availability.

As for future studies, it can be highlighted that Pack Test is originally invented as easy-touse self management tool for industrial effluent check, and environmental education for sustainability. Accordingly, the detection limit and sensitivity of conventional standard methods for water quality analysis are considerably better. Thereby certifications for water qualities are issued by only conventional standard method and the documentation is functioning in social environmental regulation. Currently, only this direction of water quality analysis is domestically and internationally recognized by government, so that how authority, such as SIRIM Berhad in Malaysian case, officially recognise the simplified tool (e.g. Pack Test) could be very critical toward to implement the new paradigm of participative water environmental management scheme. In addition, to confirm the credibility test of the tool and applicability test of Pack Test are also not yet inspired in Tropical developing countries, so that it is inevitable the research base assessment of Pack Test, and making model case activities for water-environmental issues.

\section{Conclusions}

1. It is assumed that Pack Test is a professional easy-to-use onsite water quality checker, which property is small, rapid to know result, low cost. It can be use at anywhere without any laboratory facilities.

2. The aim of this study is to examine the possibility of application of Pack Test on strategic environment assessment and environment education for sustainability, and to assess the required matters during introduction processes to Malaysia.

3. Two workshops were sampled to prove the potential function of Pack Test in environmental education and participative environmental monitoring.

4. The role of Pack Test was segregated from conventional standard methods, and because of its unique characters, it was well performed as user friendly easy-to-use water quality checker.

5. Two workshops showed strong positive potential for implementation of Pack Test in improving public environmental awareness because people can participate more effectively in water environment issues by the tool.

6. Participant's feeling in the both workshops showed strong positive potential for Pack Test.

7. It was clear that Pack Test is notable in-situ water quality checker, which has advantages over its particular methods that never rely on transport of samples to a distant laboratory for chemical analysis.

8. Then, participants were able to classify the water quality level in a short time. However, even to use Pack Test is very simple, the needs of training chance for facilitator was pointed out.

\section{Acknowledgement}

The author wants to thank Kyoritsu ChemicalCheck Lab. Corporation. for their kind support and author always deeply have impressed with cooperation received from them. Author as well appreciates Dr Akira Kikuchi for his supervision and guidance in carrying out this study. Because this is author's first paper, author deeply thanks to Abd Rahman as author's father and family for their unquestionable supports. Author wants to thank Faculty of Civil Engineering in UTM and International Water Association, and for all staffs who involved in Water awareness in conjunction with varsity boat race' program.

\section{Reference}

[1] Tippett, J., Handley, J. F. \& Ravertz, J., (2007) Meeting the challenges of sustainable development- $A$ conceptual appraisal of a new methodology of participatory ecological planning. Progress in Planning, 67: 9-98

[2] Haklay, M. (2002) Public environmental information: understanding requirements and patterns of likely public use. Area, 34:17-28.

[3] Gauthier M, et al, (2010) Public participation in strategic environmental assessment (SEA): Critical review and the Quebec (Canada) approach, Environ Impact Asses Rev, doi:10.1016/j.eiar. 2010.01.006

[4] De Stefano, L. (2010) Facing the water framework directive challenges: Baseline of stakeholder participation in European Union. Journal of Environmental Management, 91: 1332-1340.

[5] Kikuchi, A., Hakim, L., Heryanshah, A., \& Rosmaidi (2010) Significance of the Easy-to-use Water Quality Checker for Participative Environmental Monitoring and Experience Based Learning. Journal of Tropical Life Science, 1: 17-21.

[6] Sadler, B. (1996) Environmental assessment in a changing world: evaluation practice to improve performance. Hull, Canadian Environmental Assessment Agency and International Association for Impact Assessment: International Study of the 
Effectiveness of Environmental Assessment. Final Report. 300p.

[7] Fisher, T.B. (2003) Strategic Environmental Assessment in Post-modern times. Environn Impact Assess Rev., 23: 155-170.

[8] Lawrence, D.P. (2000) Planning theories and environmental impact assessment. Environ Impact Assess Rev., 20: 607-625.

[9] Mouratiadou, I. \& Moran, D, (2007) Mapping public participation in the Water Framework Directive: A case study of the Pinios River Basin, Greece. Ecological Economics, 62: 66-76.

[10] Disinger, J. (1993) Environmental Education in the K12 Curriculum: An Overview, in R. Wike (ed), Environmental Education Teacher Resource Handbook, Kraus International Pub, Milwood, NY.

[11] Schleicher, K. (1989) Beyond Environmental Education: The need for ecological Awareness. International Review of Education, 35: 257-281.

[12] Huang, G. H. \& Xia, J. (2001) Barriers to sustainable water-quality management. Journal of Environmental Management, 61: 1-23.
[13] Thompson, S. A. (1999) Water use, Management, and planning in the United States. p273-305.

[14] Greenwood, R., Mills, G. A., \& Roig, B. (2007) Trends in Analytical Chemistry. Introduction to emerging tools and their use in water monitoring, 26: 4-00.

[15] Graveline, N., Maton, L., Lu“ckge, H., Rouillard, J., Strosser, P., Palkaniete, K., Rinaudo, J. D., Taverne, D., \& Interwies, E. (2010) Trends in Analytical Chemistry. An operational perspective on potential uses and constraints of emerging tools for monitoring water quality, 29: 5-00.

[16] Pahl-Wostl, C., Tabara, D., Bouwen, R., Craps, M., Dewufl, A., Mostert, E., Ridder, D. \& Taillieu, T. (2008) The importance of social learning and culture for sustainable water management. Ecological Economics, 64: 484-495.

[17] Carlsson-Kanyama, A., Dreborg, K. H., Moll, H. C. \& Padovan, D. (2007) Participative backcasting: A tool for involving stakeholders local sustainability planning. Futures, 40: 34-46. 